\title{
CRANIOTOMIA DESCOMPRESSIVA BIFRONTAL NO TRATAMENTO DO EDEMA CEREBRAL GRAVE
}

\author{
WALTER C. PEREIRA* \\ VALFREDO J. NEVES * \\ YARA RCDRIGUES **
}

A despeito dos variados recursos medicamentosos e de terapia intensiva que atualmente dispomos, o edema cerebral ainda é um dos grandes problemas que o neurocirurgião enfrenta, ceifando a vida de numerosos pacientes. Não existe até o presente método ideal para seu tratamento, tendo sérias restrições todas as drogas empregadas, em virtude dos efeitos colaterais, que muitas vezes impedem seu uso prolongado ou mesmo sua indicação. Por outro lado, certos tipos de edema cerebral, como o que ocorre em casos de traumatismo crânio-encefálico (TCE), pouco ou nada respondem à terapia conservadora.

Desde há muito os neurocirurgiōes vêm tentando salvar a vida de doentes com edema cerebral grave mediante vários tipos de intervenção cirúrgica, que, em última análise, visam a impedir danos irreversíveis ao tronco cerebral, comprimido e deslocado por hérnias do giro hipocampal e uncus. Essas operações consistem em criar espaço para que a pressão do cérebro, aumentado de volume pelo edema, não se exerça sobre o tronco cerebral e vasos situados em sua vizinhança. Com esta finalidade foram preconizadas craniectomias descompressivas unilaterais mais ou menos amplas ${ }^{3,6,10,11}$ ou bilaterais extensas ${ }^{2}$, criando espaço para o cérebro expandir-se externamente através de aberturas na dura-máter, assim como amputações de partes do parênquima cerebral edemaciado, de forma tal que sua expansão se fizesse internamente 8,8 e a associação de ambos os métodos ${ }^{5}$. A maioria destes procedimentos, contudo, foi abandonada pelos resultados precários que alguns proporcionavam ou pelas complicações graves que outros provocavam.

Kjellberg e Prieto ${ }^{\top}$ descreveram em 1971 outro tipo de operação, indicada para casos de edema cerebral grave e não reversivel com as medidas conservadoras empregadas criteriosamente, que consiste em craniotomia descompressiva bifrontal (CDB). Desde 1974 vimos praticando este tipo de intervenção em casos selecionados, geralmente de TCE, depois de nos termos decepcionado com outros métodos cirúrgicos que até então utilizávamos, sendo o propósito deste trabalho a apresentação dos resultados obtidos em 12 doentes.

Trabalho realizado no Hospital São Joaquim da Real e Benemérita Sociedade Portuguesa de Beneficencia de São Paulo: * Chefe do Serviço de Neurocirurgia; ** Neurocirurgiăo Assistente; *** Residente. 


\section{CASUISTICA E METOdo}

A tabela 1 fornece a identificação dos 12 doentes em que praticamos CDB, assinalando também os principais dados do exame neurológico pré-operatório e a etiologia da afecçåo. Além dos dados registrados nessa tabela, devemos mencionar que distúrbios do ritmo e/ou da frequéncia respiratória estavam presentes em todos pacientes na ocasião em que se indicou a CDB. Assim, dois se apresentavam em apnéia (casos 5 e 9). 7 tinham ritmo do tipo Scheyne-Stokes (casos 3, 4, 6. 7, 8, 11 e 12) e três, respiração rápida e superficial (casos 1,2 e 10).

\begin{tabular}{|c|c|c|c|c|c|c|}
\hline Jaso & Nome & $\begin{array}{l}\text { Idade } \\
\text { (anos) }\end{array}$ & Sexo & Registro & $\begin{array}{c}\text { Quadro } \\
\text { neurológico }\end{array}$ & Etiologia \\
\hline 1 & LHMF & 30 & $\mathbf{F}$ & 054.510 & $\begin{array}{l}\text { Coma grau IV } \\
\text { midriase D } \\
\text { descerebração } \mathbf{E}\end{array}$ & TCE \\
\hline 2 & JLS & 31 & $\mathbf{M}$ & 056.359 & $\begin{array}{l}\text { Coma grau III } \\
\text { midriase D } \\
\text { hemiplegia D }\end{array}$ & TCE \\
\hline 3 & JST & 44 & $\mathbf{F}$ & 058.780 & $\begin{array}{l}\text { Coma grau III } \\
\text { midriase D } \\
\text { descerebração } \mathrm{B}\end{array}$ & TCE \\
\hline 4 & VLGK & 27 & $F$ & 056.909 & $\begin{array}{l}\text { Coma grau III } \\
\text { miose B } \\
\text { descerebração B }\end{array}$ & TCE \\
\hline 5 & $\mathbf{Y P}$ & 20 & $F$ & 061.217 & $\begin{array}{l}\text { Coma grau III } \\
\text { midriase B } \\
\text { descerebraçăo B }\end{array}$ & TCE \\
\hline 6 & $\mathbf{M M}$ & 17 & $\mathbf{F}$ & 064.627 & $\begin{array}{l}\text { Coma grau III } \\
\text { míose B } \\
\text { descerebração B }\end{array}$ & TCE \\
\hline 7 & FSS & 31 & $\mathbf{M}$ & 069.521 & $\begin{array}{l}\text { Coma grau III } \\
\text { miose B } \\
\text { descerebração B }\end{array}$ & TCE \\
\hline 8 & RMS & 23 & $\mathbf{M}$ & 082.299 & $\begin{array}{l}\text { Coma grau III } \\
\text { midriase D } \\
\text { hemiplegia } D\end{array}$ & TCE \\
\hline 9 & RF & 42 & $\mathbf{M}$ & 082.469 & $\begin{array}{l}\text { Coma grau IV } \\
\text { midriase B } \\
\text { arreflexia }\end{array}$ & $\begin{array}{c}\text { Malformação } \\
\text { angiomatosa }\end{array}$ \\
\hline 10 & SM & 36 & $\mathbf{M}$ & 086.225 & $\begin{array}{l}\text { Coma grau III } \\
\text { descerebraçẵo B }\end{array}$ & TCE \\
\hline 11 & TCC & 1 & $\mathbf{M}$ & 092.396 & $\begin{array}{l}\text { Coma grau III } \\
\text { midriase B } \\
\text { descerebração B }\end{array}$ & $\begin{array}{l}\text { Sindrome } \\
\text { de Reye }\end{array}$ \\
\hline 12 & JCR & 56 & $F$ & 094.976 & $\begin{array}{l}\text { Coma grau III } \\
\text { midriase E } \\
\text { descerebraçăo B }\end{array}$ & TCE \\
\hline
\end{tabular}

Tabela 1 - Identificação, principais dados do exame neurológico no pré-operatório da $C D B$ e etiologia do edema cerebral: $B=$ bilateral; $D=$ Direita; $E=$ esquerda; $H=$ feminino; $M=$ masculino; $T C E=$ traumatismo rranio-encefalico. 
Estudo angiográfico cerebral foi praticado no pré-operatório em todos os doentes e, na maioria, repetido uma ou mais vezes no pós-operatório. Ambos os territórios carotídeos foram examinados, tendo os achados angiográficos contribusdo decisivamente para a indicação da CDB.

Técnica cirúrgica - A CDB foi praticada segundo a técnica descrita originalmente por Kjellberg e Prieto 7, com algumas modificações gerais ou particulares, de acorło com os achados operatórios em cada caso. Esta técnica consiste em incisão coronária do couro cabeludo, que se estende látero-inferiormente até as arcadas zigomáticas de ambos os lados; após descolamento subperiostal do couro cabeludo até o nível das arcadas orbitárias, pratica-se craniotomia, que se estende desde a linha da sutura coronária até cerca de um centímetro acima das arcadas orbitárias e, lateralmente, até a parte mais baixa possivel da fossa temporal, sob a inserção do músculo temporal previamente desinserido. O retalho osseo frontal foi retirado em bloco único em todos os pacientes, exceto em uma criança (caso 11), na qual este foi dividido em duas metades na linha mediossagital; neste doente foram também retirados ambos os ossos parietais em quase toda extensão, deixando-se apenas estreita faixa óssea cobrindo o seio sagital superior desde a regiăo da sutura lambdóide até a bregmática, visando à proteçăo deste seio (Fig. 1).

A dura-mater é aberta amplamente, iniciando-se esse procedimento a cerca de um centímetro da borda óssea, que é acompanhada em toda extensão; o seio sagital superior
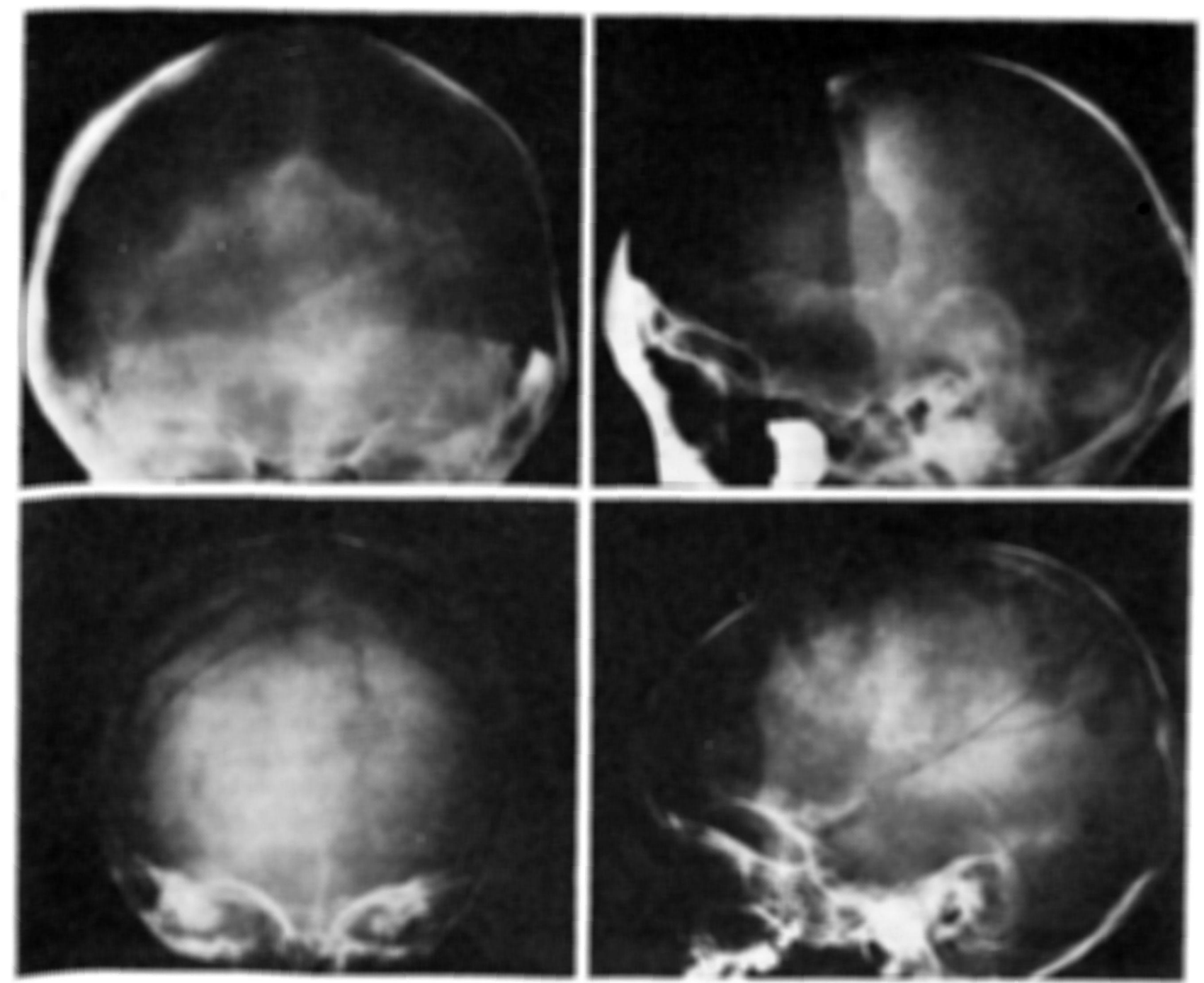

Fig. 1 - Craniogramas simples nas incidências de frente $e$ perfil. Em cima, extensão habitual da CDB, notando-se que uma das fossas médias foi mais descomprimida que a outra (SM, caso 10); em baixo, radiografias feitas apos a recolocação óssea em caso de $C D B$ acrescida da retirada quase total de ambos os ossos parietais (TCC, caso 11). 
é ligado em sua porção mais anterior, sendo a seguir seccionado, assim como a foice do cérebro, que é desinserida da apófise crista galli. Desta maneira os hemisférios cerebrais ficam livres para expandir-se súpero-anteriormente. Uma modificaçåo técnica, que introduzimos desde as primeiras intervenções, visando ao melhor isolamento entre os seios frontais geralmente abertos e a cavidade craniana, foi a sutura da borda anterior (basal) da dura-mater ao periósteo do osso frontal logo acima das arcadas orbitárias e região da glabela, interpondo fragmentos musculares entre aquela membrana e a cavidade dos seios frontais, que permanece assim bem tamponada; outra vantagem deste procedimento é que facilita a plástica dural a ser feita ulteriormente, pois evita retraçåo desta porçåo da dura-mater em direçăo a base da fossa craniana anterior. Em operações subsequentes verificamos ser necessária, na maioria dos casos, ampliaçåo da abertura óssea em direçăo à parede lateral da fossa média, a fim de possibilitar melhor liberação da ponta do lobo temporal, bem como explorar com mais facilidade esta regiåo. Ao contrário do que afirmam Kjellberg e Prieto, nåo conseguimos por esta vía de acesso visibilização das porções posteriores dos lobos parietais e, menos ainda, dos occipitais, porque o edema cerebral impede que sejam praticadas retrações do tecido por meio de espátulas ou manobras digitais. Nas CDB bem extensas, como praticamos atualmente, pode-se com facilidade examinar inteiramente os lobos frontais, os polos dos temporais e a parte anterior dos parietais.

Em caso algum fizemos plástica da dura-mater durante este tempo cirúrgico, limitando-nos a deixá-la completamente livre sobre o córtex cerebral, sendo o fechamento da ferida operatória garantido apenas pela sutura em plano único do couro cabeludo com pontos totais e separados de mononylon 2-0. Em alguns pacientes, em que havia sangramento difuso em zonas contusas, colocamos dreno tubular de borracha no espaço subgaleal, retirado 24 ou 48 horas depois.

A cranioplastia, praticada de 7 a 28 dias após a CDB, foi feita com a reposiçâo do fragmento osseo do próprio paciente, conservado em glicerina pura, depois de termos comprovado sua esterilidade em meios de cultura para bactérias e fungos. Em todos os casos a plástica da dura-mater, que sempre sofre certo grau de retraçăo e aderência, foi feita com fragmentos de periósteo, aponeurose epicranica ou fascia lata retirados nessa ocasiåo do próprio doente.

Em 6 pacientes (casos 2, 4, 6, 7, 10 e 11) a $\mathrm{CDB}$ foi a primeira intervençăo cirúrgica realizada, porquanto apresentavam clínica e angiograficamente sinais de edema cerebral intenso, associado ou năo a hematomas subdurais ou intracerebrais. Nos outros 6 a CDB foi indicada após outro tipo de cirurgia, como mostra a tabela 2; nestes doentes ocorreu agravamento neurológico depois destas intervenções cirúrgicas, surgindo sinais clínicos e anglográficos de edema cerebral difuso ou localizado na regiâo do lobo temporal, uni ou bilateralmente, o que nos levou a praticar CDB dentro dos primeiros três dias após a operaçăo inicial.

Em três pacientes tivemos necessidade de fazer revisão da CDB (casos 5, 7 e 8); sendo a doente YP (caso 5) reoperada duas vezes. Nestes casos a evoluçáo pós-operatória do quadro neurológico, assim como a tensăo progressivamente maior da regiăo operada, apesar da terapia concomitante com dexametasona e diuréticos osmóticos, levou-nos a praticar novas angiografias cerebrais, que demonstraram ainda sinais de edema cerebral e/ou de hérnias transtentoriais descendentes. Nesses doentes a revisão cirúrgica revelou a presença de focos de necrose cortical, hematomas subdurais e/ou intraparenquimatosos nåo existentes na CDB praticada anteriormente; em todos estes pacientes, além da exérese das zonas necrosadas e drenagem de hematomas, a falha óssea foi ampliada em direçăo à parede externa da fossa média do lado comprometido.

O pós-operatório de todos os pacientes foi feito na Unidade de Terapia Intensiva, durante longos períodos de tempo em alguns casos, onde, além da vigilancia contínua do neurocirurgižo, era feito controle frequente de vários parametros fisiológicos por meio de exames laboratoriais. Apesar de todos estes cuidados, visando principalmente às funçóes respiratórias, cardíaca e renal, bem como ao controle hidreletrolitico, a maioria dos pacientes apresentou várias complicaçós, mormente respiratórias. Todos os doentes receberam durante o pós-operatório imediato dexametasona nas doses de 2 a $4 \mathrm{mg}$, administrada por via intravenosa cada 4 ou 6 horas e sendo mantida por 7 a 


\begin{tabular}{|c|c|c|c|}
\hline Caso & Operações anteriores à CDB (achados) & $\begin{array}{l}\text { Revisões } \\
\text { da CDB }\end{array}$ & Obitos \\
\hline 1 & $\begin{array}{l}\text { Craniectomia temporal } \mathrm{D} \text {. } \\
\text { Hematoma subdural e contusão cerebral. }\end{array}$ & - & + \\
\hline 3 & $\begin{array}{l}\text { Craniotomia bifrontal. } \\
\text { Fratura do andar anterior e fistula de LCR. }\end{array}$ & - & + \\
\hline 5 & $\begin{array}{l}\text { Craniectomia temporal } \mathbf{E} \text {. } \\
\text { Hematoma subdural e contusão cerebral. }\end{array}$ & 2 & - \\
\hline 7 & - & 1 & + \\
\hline 8 & $\begin{array}{l}\text { Craniotomia temporal D. } \\
\text { Hematoma extradural e contusăo cerebral contralateral. }\end{array}$ & 1 & - \\
\hline 9 & Craniotomia frontal E. & $\cdots$ & + \\
\hline 12 & $\begin{array}{l}\text { Craniectomia temporal E. } \\
\text { Hematoma subdural e contusão cerebral. }\end{array}$ & - & + \\
\hline
\end{tabular}

Tabela 2 - Intempngסes cirirgicas praticadas anteriormente, revisoes da CDB e 6bitos em 6 pacientes.

15 dias. Na maioria dos pacientes foi também empregado manitol ou glicerol intravenosamente, tomando-se por base a tensăo da regiăo operada e os sinais neurológicos; a utilização destas drogas variou de 3 a 7 dias.

\section{RESULTADOS}

Dos 12 doentes em que praticamos CDB, 6 sobreviveram e 6 faleceram, estando assinaladas na tabela 3 as condiçóes neurológicas na ocasiăo da alta ou do b́bito, as complicações graves responsáveis pelo óbito em 4 pacientes e o tempo de permanéncia hospitalar após a CDB.

Dos 6 pacientes que sobreviveram, 5 tiveram alta com condiçర̃es neurológicas muito satisfatórias, levando-se em conta a gravidade do quadro pré-operatório (casos 2, 5, 6, 10 e 11), e um (caso 8) foi removido para outro hospital dois meses depois da CDB em coma vigil e descorticação bilateral. A paciente MM (caso 6), que recebeu alta com plena lucidez, discreta paraparesia crural flácida e pneumencefalograma dentro dos limites da normalidade (Fig. 2), apresentava desde a infancia sequela de poliomielite em ambos os membros inferiores, deficit este que se agravou durante os 4 meses em que permaneceu internada. O doente TCC (caso 11), cujo elema cerebral estava relacionado a encefalopatia grave da sindrome de Reye, teve melhora imediata dos sinais de compressão do tronco cerebral após a $\mathrm{CDB}$, que neste caso foi muito ampliada, retirando-se a maior parte dos ossos parietais em virtude do edema ser muito intenso, permanecendo o cérebro comprimido ao nível da borda posterior da craniotomia inicialmente planejada; a fim de evitarmos hérnia cerebral a este nível fomos obrigados a estender a craniotomia até as proximidades do sutura lambdóide, preservando apenas 

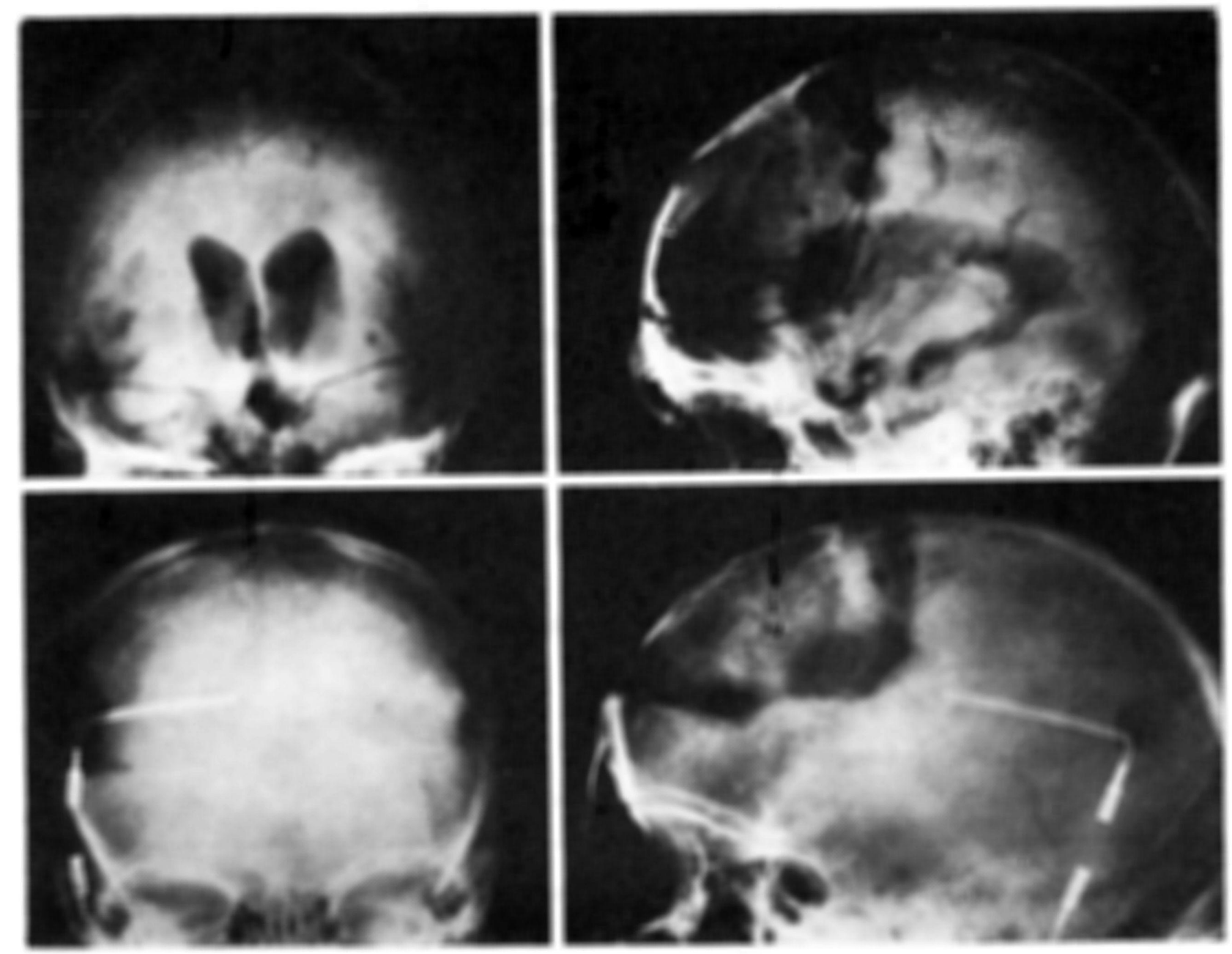

Fig. - Em cima, pneumencefalograma praticado \& meses apbs a CDB (MM, caso 6); em baixo, complicaçes ocorridas no paciente JL8, caso 8: absorço acentuada do retalho ós8eo $e$ hidrocefalia de pressøo normal.

estreita faixa óssea sobre o seio sagital superior (Fig. 1). A involução ulterior do quadro neurológico foi lenta, tendo recebido alta 20 dias depois da CDB com boa contactuaçăo e sinais discretos de liberação piramidal bilateral. Fm três pacientes (casos 2, 5 e 10) a recuperação foi praticamente completa, podendo retornar às suas ocupaçð̃es habituais, com pouca limitação funcional, logo após a alta hospitalar.

Entre os 6 pacientes que faleceram apenas dois (casos 4 e 9) năo manifestaram melhora alguma do quadro neurológico após a CDB, tendo, pelo contrário, piorado progressivamente; nestes casos, presumivelmente, as lesర̃es provocadas pela compressão e distorçăo do tronco já se tinham tornado irreversiveis, de nada valendo a descompressão. Nos outros 4 doentes o óbito foi relacionado a complicaç⿸丆es graves precoces ou tardias, tendo sido observado após a CDB desaparecimento imediato (caso 1) ou progressivo (casos 3,8 e 12) dos sinais atribuiveis à compressão do tronco cerebral. Na paciente JST (caso 3) o obito ocorreu 17 dias depois da CDB, sendo imputado a septicemia por estafilococos aureos e pseudomonas, cujo foco foi localizado em fratura exposta da tíbia esquerda. A paciente JCR (caso 12), além dos sinais neurológicos graves e respiraçăo do tipo Scheyne-Stokes, apresentava hipertensão arterial muito elevada, com a pressão minima oscilando entre 14 e $18 \mathrm{~mm}$ de $\mathrm{Hg}$, não controlável mesmo com a administração intravenosa em microgotas de nitroprussiato de sódio; imediatamente após a CDB houve melhora nitida do quadro neurológico e os niveis tensoriais se normalizaram espontaneamente; o obito ocorreu no $11^{\circ}$ de pós-operatório, causado por parada cardíaca súbita, que fol atribuida a enfarte extenso do mícárdio, uma vez 


\begin{tabular}{|c|c|c|c|c|}
\hline Caso & $\begin{array}{l}\text { Condições neurológicas } \\
\text { na ocasiăo da alta ou do óbito }\end{array}$ & Complicaçōes & Evoluçăo & $\begin{array}{l}\text { Tempo de } \\
\text { internação }\end{array}$ \\
\hline 1 & Melhora acentuada & $\begin{array}{l}\text { Embolia } \\
\text { pulminar }\end{array}$ & Obito & 2 dias \\
\hline 2 & $\begin{array}{l}\text { Lúcido } \\
\text { discreta hemiparesia } \mathbf{E}\end{array}$ & - & Alta & 15 dias \\
\hline 3 & Melhora progressiva & Septicemia & Óbito & 17 dias \\
\hline 4 & Piora progressova & - & Obito & 2 dias \\
\hline 5 & $\begin{array}{l}\text { Lúcida } \\
\text { Sem deficits motores }\end{array}$ & - & Alta & 4 meses \\
\hline 6 & $\begin{array}{l}\text { Lúcida } \\
\text { discreta paraparesia crural }\end{array}$ & - & Alta & 4 meses \\
\hline 7 & $\begin{array}{l}\text { Coma vigil } \\
\text { descorticaçăo } B\end{array}$ & Septicemia & óbito & 8 meses \\
\hline 8 & $\begin{array}{l}\text { Coma vigil } \\
\text { descorticaçăo } \mathrm{B}\end{array}$ & - & Alta & 2 meses \\
\hline 9 & Piora progressiva & - & obito & $1 \mathrm{dia}$ \\
\hline 10 & $\begin{array}{l}\text { Lúcido } \\
\text { discreta hemiparesia } D\end{array}$ & - & Alta & 2 meses \\
\hline 11 & $\begin{array}{l}\text { Boa contactuaçăo } \\
\text { sinais piramidais } B\end{array}$ & - & Alta & 20 dias \\
\hline 12 & Melhora progressiva & $\begin{array}{l}\text { Enfarte do } \\
\text { miocárdio }\end{array}$ & óbito & 11 dias \\
\hline
\end{tabular}

Tabela 3 - Evolucão pós-operatoria: condições neuroloyicas na ocasião da alta ou do óbito, complicaçós relacionadas com o obito $e$ tempo de internacão após a $C D B$.

que o eletrocardiograma feito poucos dias antes revelara alterações difusas e graves da repolarização ventricular. O único paciente que faleceu tardiamente (caso 7), apresentava-se na ocasião do óbito em coma vigil e descorticação bilateral, decorrente de atrofia cerebral intensa e difusa, comprovada por pneumencefalograma.

Em 4 dos pacientes que faleceram a $\mathrm{CDB}$ não foi a primeira intervençăo cirúrgíca praticada, tendo sido indicada ulteriormente em virtude do surgimento de sinais clínicos e angiográficos de elema cerebral grave, comprometendo o tronco cerebral. Apenas um dos três doentes em que foi feita revisão da $\mathrm{CDB}$ faleceu, embora o óbito tenha ocorrido ? meses depois desta operação em consequência a septicemia.

Entre os sobreviventes foram observadas poucas complicações depois da alta hospitalar. O paciente JLS (caso 2) cerca de 8 meses após o TCE apresentou quadro sugestivo de hidrocefalia de pressão normal, comprovado por pneumencéfalo e cisternocintilografia, tendo sido instalado sistema de derivação ventriculoperitoneal. Nesse mesmo paciente e em outra (caso 5) houve absorção parcial do retalho ósseo da craniotomia (Fig. 2), sendo necessário em um deles (caso 2) praticar-se cranioplastia com metilmetacrilato dois anos após a CDB. 


\section{COMENTARIOS}

O edema cerebral grave continua sendo uma das maiores preocupaçōes do neurocirurgião e trabalhos recentemente elaborados em centros adiantados mostram que a solução deste problema está ainda longe de ser encontrada 1, 7. Certos tipos de edema cerebral, como o que se manifesta no TCE grave, não respondem às drogas que se mostram eficazes quando está relacionado com outras afecções, mormente neoplásicas, inflamatórias e vasculares. Na contusão cerebral grave as lesões são difusas, envolvendo o parenquima nervoso e seus vasos sanguineos, que sofrem rotura ou obstrução, causando edema intenso e de difícil reversão. A inelasticidade do estojo craniano, por outro lado, contribui para a agravação do quadro, pois, além de comprimir o encéfalo, prejudicando ainda mais sua irrigação, obriga-o a deslocar-se medial e inferiormente, dando origem a hérnias transtentoriais descendentes, as quais comprimem e distorcem o tronco cerebral, levando a quadros neurológicos de suma gravidade. E importante assinalar que a evolução dos mecanismos que culminam desta maneira não é rápida, surgindo geralmente algumas horas ou dias após o TCE. Habitualmente a fase crítica da contusão cerebral grave situa-se no quarto ou quinto dias de evolução.

Um problema, portanto, que o neurocirurgião enfrenta de início é estabelecer o diagnóstico diferencial entre lesões primárias do tronco cerebral, causadas diretamente pelo TCE, das provocadas secundariamente por compressão. Isto não é difícil quando os sinais neurológicos vão surgindo após a internação do paciente, mas é praticamente impossível quando este já chega ao hospital com o quadro instalado e sem dados evolutivos que permitam reconstituir a cronologia dos eventos.

A análise da literatura sobre os resultados de cranıectomias ou craniotomias descompressivas, que há longo tempo são empregadas como tratamento paliativo de doentes com edema cerebral grave de variadas etiologias, não é alentadora. Estas operações são em geral indicadas como recursos extremos em pacientes com neoplasias cerebrais inextirpáveis ou em casos de TCE muito graves.

Como Ransohoff e col. 10 tivemos ocasião de observar casos em que a craniotomia descompressiva unilateral, praticada em doentes com contusão cerebral e sinais neurológicos focais, causou sua piora imediata ou poucas horas ou dias depois. Estes autores consideram imprescindível a angiografia carotídea bilateral antes da indicação deste tipo de cirurgia, imputando à presença de lesões contralaterais ao hemisfério cerebral descomprimido a agravação, muitas vezes fatal, destes enfermos. Chegam a admitir ser aconselhável a prática de craniotomia descompressiva bilateral simultânea em tais casos, a fim de evitar o deslocamento lateral do tronco cerebral, que pode levar à morte em poucos minutos. Tivemos a infelicidade de presenciar casos em que a craniotomia descompressiva unilateral provocou, durante $o$ ato cirúrgico, tal herniação do cérebro que as calibrosas veias tributárias do seio sagital superior se romperam, tornando impossível qualquer medida para impedir o óbito do doente.

Partindo do pressuposto que lesões múltiplas são a regra no TCE grave, cada vez mais nos convencemos de que o estudo angiográfico cerebral deva ser o mais completo possivel nestes pacientes, nunca se limitando à carótido-angiografia unilateral. Além disso, a repetição desse exame deve ser sempre cogitada 
durante a evolução do caso, pois, frequentemente, o estudo angiográfico praticado precocemente pode não evidenciar anormalidades, que serão detectadas em angiografias ulteriores.

A CDB tem sua indicação precipua no TCE grave, não só por sua grande e crescente incidência como também pela alta mortalidade e morbilidade que $o$ acompanham. Nesta afeç̧ão a CDB propicia condições para recuperação de doentes que, de outra forma, fatalmente morreriam. Obviamente, esta melhora dependerá do grau de lesão existente no momento em que se pratica a operação, sendo a indicação precoce condição básica para o bom êxito da cirurgia. No que tange a este aspecto, pudemos verificar que os sinais angiográficos geralmente precedem de várias horas, ou mesmo dias, o desencadeamento do quadro neurológico grave que, de regra, motiva a $\mathrm{CDB}$. Por este motivo atualmente julgamos que o critério para indicar esta operação deva basear-se fundamentalmente nos achados angiográficos, que prenunciam o agravamento neurológico, o que, com toda certeza, propiciaria melhores resultados. O inverso é também verdadeiro, ou seja, a inexistência de sinais angiográficos de hérnias transtentoriais ou de aumento de volume dos lobos temporais, em pacientes com sofrimento do tronco cerebral alto, contra-indica a $\mathrm{CDB}$, pois, nestes casos, serão primárias as lesões ao nível desta estrutura.

Ao contrário do que ocorre em outros tipos de craniotomia descompressiva, a CDB possibilita o deslocamento do cérebro edemaciado para cima e para frente, - que, aparentemente, não causa danos ao tronco cerebral. Em angiografias pós-operatórias observa-se perfeitamente esse deslocamento, elevando-se o grupo silviano, o que sugere o desengasgamento das porções internas dos lobos temporais (Fig. 3).

$\mathrm{Na}$ casuística que analisamos neste trabalho, a CDB foi praticada em 10 pacientes com TCE grave. Todos estes doentes, exceto um (caso 1), apresentavam sinais neurológicos de compressão bilateral do tronco cerebral. $O$ estudo angiográfico bilateral demonstrou em todos sinais de edema e/ou de massa expansiva uni ou bilateral, levando-nos a indicar CDB. O quadro pré-operatório destes pacientes era de extrema gravidade, podendo ser considerado irreversível com medidas terapêuticas conservadoras. Após a operação, em 9 destes doentes (90\%) houve desaparecimento dos sinais de sofrimento do tronco cerebral, observado imediatamente em um (caso 1) e de maneira progressiva nos outros 8 $(\operatorname{casos} 2,3,5,6,7,8,10$ e 12). Apenas em um dos pacientes com TCE não ocorreu melhora alguma (caso 4), vindo este a falecer dois dias depois da CDB; neste caso as lesões ao nível do tronco cerebral eram já irreversiveis quando se praticou a CDB. Em outros 4 doentes o óbito decorreu de complicações graves, não relacionadas diretamente ao $\mathrm{TCE}$, tendo três deles (casos 1, 3 e 12) falecido nos primeiros 17 dias após a $\mathrm{CDB}$ e um (caso 7), 8 meses depois, apresentando-se nesta ocasião em coma vigil e descorticação bilateral, consequente à atrofia cerebral difusa e acentuada.

Quatro (40\%) dos pacientes com TCE em que praticamos CDB permanecem vivos e com recuperação psíquica e motora muito satisfatórias (casos 2, 5, 6 e 10) e um (caso 8) apresentava-se em coma vigil e descorticação bilateral dois meses depois da operação, quando foi removido para outro hospital. 

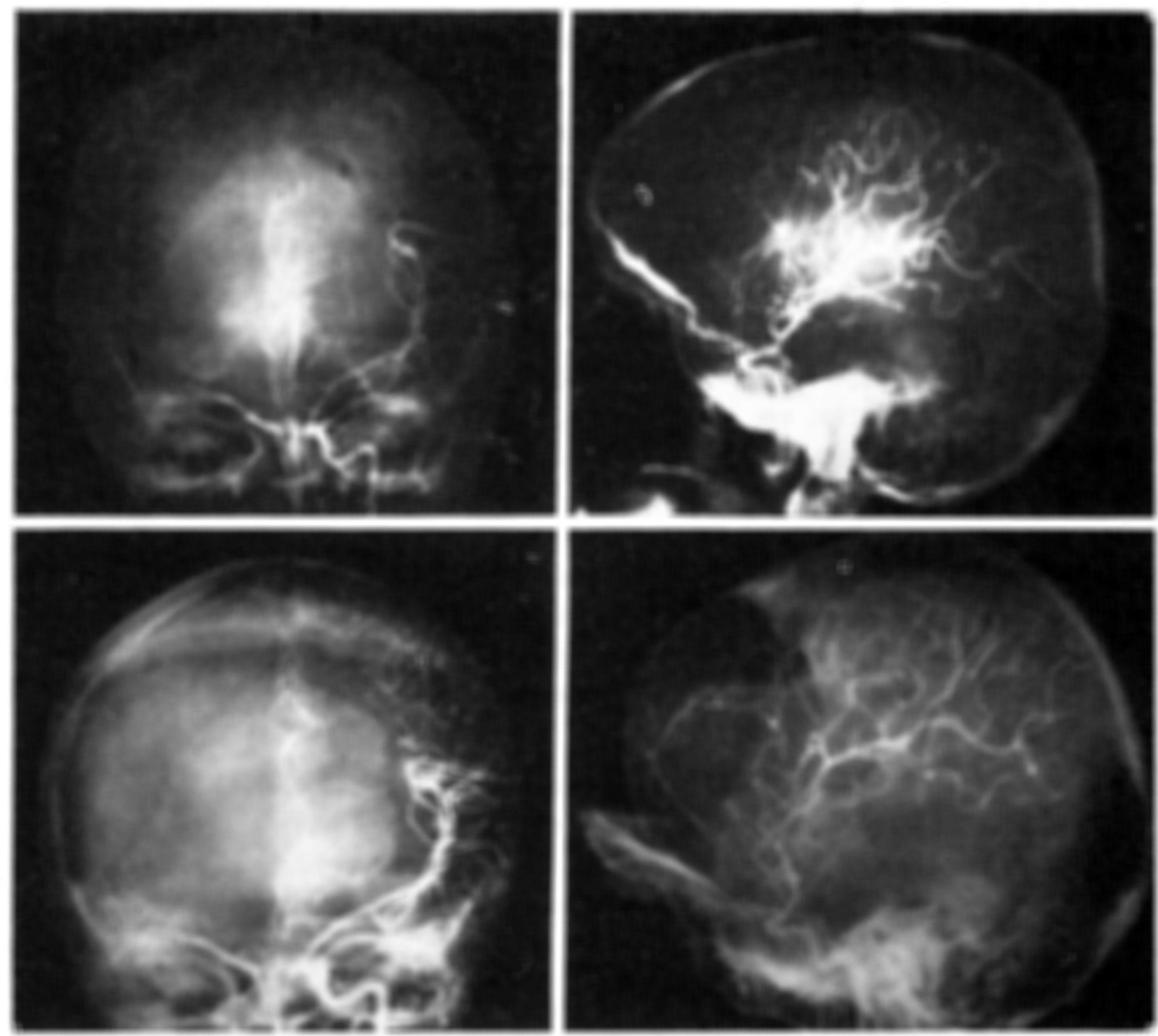

Fig. s - Angiografia carotidea esquerda nas incidencias de frente $e$ perfil praticada na paciente $Y P$, caso 5. Em cima (pré-operatório), observa-se elevaşo do grupo silviano e desvio lateral da artéria cerebral anterior; em baixo (posoperatório imediato), nota-se que houve acentuaço da elevaço do grupo silviano $e$ que a artéria cerebral anterior deslocou-se para frente, não 'havendo mais desvio lateral desta.

Os achados cirúrgicos nos pacientes com TCE revelaram falta de correlação entre a intensidade e extensão das lesões observadas e o quadro neurológico, frequentemente pouco expressivo durante as primeiras horas ou dias de internação, assim como com os achados angiográficos. Em todos estes pacientes foram encontradas, durante a exploração cirúrgica, lesões extensas ou difusas do tecido cerebral, associadas a hematomas subdurais e/ou intracerebrais, embora fossem mais conspícuas em determinadas regiōes, mormente polos frontais e temporais. Da mesma forma, nos doentes em que se fez necessária revisão da $\mathrm{CDB}$ foram encontradas lesões não evidentes anteriormente, o que demonstra a possibilidade destas continuarem progredindo durante vários dias, impondo vigilância clínica contínua e repetição do exame angiográfico, sempre que a tensão ao nível da região operada mostrar-se elevada e/ou os sinais neurológicos se agravarem. 
Apenas em dois doentes desta casuística a $\mathrm{CDB}$ foi indicada em afeç̧ões não traumáticas. O paciente RF (caso 9) foi operado com quadro neurológico de extrema gravidade (apnéia, coma profundo, midríase bilateral e arreflexia global), instalado poucas horas após exérese de malformação angiomatosa frontal esquerda; não se observou melhora alguma do quadro, vindo a falecer 24 horas depois da CDB. Quadros neurológicos de tal gravidade aparentemente contraindicariam qualquer tentativa cirúrgica; no entanto, a paciente YP (caso 5), que se constituiu em um dos nossos melhores resultados, foi também operada em apnéia, cuma profundo, midriase e descerebração bilaterais. É, de fato, muito difícil tomar-se a decisão de indicar ou não a $\mathrm{CDB}$ diante de um caso desta natureza, pois, se a indicação precoce, fundamentada nos achados angiográficos, seja obviamente preferível, é também verdadeiro que muitas vezes não temos a oportunidade de fazê-lo, como ocorreu em todos os doentes desta casuistica. Parece-nos, purtanto, que qualquer tentativa será válida se existir a mínima possibilidade de salvar a vida do doente, principalmente quando os sinais de comprometimento do tronco cerebral tiverem surgido há pouco tempo.

No paciente TCC (caso 11) a CDB foi indicada para tratamento paliativo de intenso edema cerebral, irreversível com todas as medidas conservadoras empregadas, no $7^{\circ}$ dia de evolução da encefalopatia da sindrome de Reye, imediatamente após o surgimento de sinais de compressão do tronco cerebral (coma profundo, midríase e descerebração bilaterais). Neste caso o resultado foi altamente satisfatório, havendo regressão imediata desses sinais. Caso semelhante foi registrado recentemente na literatura ${ }^{1}$, sendo considerado pelos, autores o primeiro em que tal conduta foi tomada, sustando a marcha quase sempre fatal dessa moléstia.

Nossos resultados com a CDB foram melhores que os referidos por Kjellberg e Prieto ?, que somente obtiveram sobrevida em $18 \%$ dos 73 doentes operados, na grande maioria após TCE, utilizando critérios idênticos aos nossos para a indicação cirúrgica. Além disso, quanto à qualidade da sobrevida, os resultados em nossa casuistica foram também superiores, porquanto apenas 4 de seus doentes tiveram recuperação neurológica e mental totais. Estes autores relatam que outros 22\% dos doentes operados apresentaram melhora evidente após a CDB, falecendo por outras causas entre três e 38 dias depois da intervenção cirúrgica. De 6 pacientes operados em apnéia, apenas dois sobreviveram, permanecendo, porém, um deles em estado comatoso e respondendo somente a estímulos dolorosos. Os resultados foram melhores em doentes com TCE (22\%) que em casos de hemorragia meníngea não traumática $(12,5 \%)$, concluindo ter a $\mathrm{CDB}$ sua principal indicação na contusão cerebral grave.

Podemos supor que os melhores resultados em nossa casuística se devam aos cuidados pós-operatórios, que mereceram especial atenção, controlando-se com rigor as funções vitais dos pacientes em unidade de terapia intensiva, assim como ao seguimento clínico-angiográfico, feito de maneira sistemática, sendo praticadas revisões da CDB sempre que isso se mostrasse necessário.

Um aspecto que nos parece importante ressaltar, embora não encontremos explicação clara para o fato, é que a maioria dos óbitos (4 em 6) ocorreu em doentes nos quais a CDB foi praticada após outro tipo de intervenção neurocirúrgica. 
Gonçalves da Silva e col. 4 publicaram recentemente os resultados obtidos com craniotomias descompressivas (20 unilaterais, 5 bilaterais e $5 \mathrm{CDB}$ ) em 30 pacientes, 26 dos quais com TCE. Seus resultados foram muito satisfatórios quanto à sobrevida $(46,6 \%)$, havendo, porém, em apenas $16,6 \%$ dos pacientes ausência de seqüelas neurológicas. Além disso, somente 7 dos 16 sobreviventes tinham apresentado antes da CDB postura em descerebração uni ou bilateral, que nestes casos foi sempre consequente a TCE. Estes autores tiveram maus resultados com craniotomia descompressiva bilateral e $\mathrm{CDB}$, referindo mortalidade de $80 \%$ nos pacientes operados segundo estas técnicas; com craniotomia descompressiva unilateral, contudo, a taxa de óbitos foi de apenas $40 \%$. Tais resultados sâo surpreendentes quando comparados com os fornecidos pela literatura pertinente e com nossa própria experiência. Talvez o fato de mais da metade dos doentes que sobreviveram não tivessem apresentado sinais de comprometimento do tronco cerebral, previamente à cirurgia descompressiva, possa explicar esses resultados. Por outro lado, não existem no trabalho de Gonçalves da Silva e col. referências aos achados angiográficos pré-operatórios, elemento de capital importância para indicação de qualquer tipo de craniotomia descompressiva, principalmente se unilateral.

A nosso ver a $C D B$, se bem que não seja ainda solução definitiva para o problema, é atualmente o método cirúrgico que melhores resultados pode oferecer na recuperação de doentes com edema cerebral grave e irreversivel com os recursos convencionais de tratamento. Nossa experiência é ainda pequena, pois somente há dois anos vimos empregando esta técnica em casos bem selecionados. A observação da evolução destes casos, contudo, nos autoriza supor que os resultados seriam certamente mais compensadores se a CDB fosse indicada precocemente, antes do comprometimento sério do tronco cerebral, mormente em casos de TCE, tomando-se como base o estudo angiográfico cerebral, que fornece elementos de valor premunitório quanto à evolução provável do caso.

\section{RESUMO}

São apresentados os resultados obtidos com craniotomia descompressiva bifrontal ampla em 12 doentes com edema cerebral grave e irreversível com os métodos convencionais de tratamento, provocado em 10 por traumatismo crânioencefálico. Todos os pacientes apresentavam quadro neurológico muito grave, com sinais de comprometimento do tronco cerebral superior. Angiografia carotídea bilateral foi praticada sistematicamente, tanto no pré como no pós-operatório, constituindo-se no fator decisivo para a indicação cirúrgica.

Seis $(50 \%)$ dos doentes sobreviveram, apresentando $5(41,6 \%)$ recuperação neurológica e psíquica praticamente totais. Levando em conta estes resultados, consideramos esta técnica cirúrgica o melhor recurso de tratamento em tais casos, máxime se indicada precocemente. São necessários, contudo, cuidados pós-operatórios especiais com estes pacientes, que devem, sempre que possível, ser mantidos em unidade de terapia intensiva, em virtude da grande incidência de complicações, mormente respiratórias. 


\section{SUMMARY}

\section{Bifrontal decompressive craniotomy as treatment of severe cerebral edema}

The authors present the results observed with large bifrontal decompressive craniotomy performed on 12 patients with severe cerebral edema, 10 of them related to cerebral contusion, which did not respond to conventional methods of therapy. All patients had before surgery very bad prognosis, with severe neurological signs of higher brain stem compression. Bilateral carotid angiography was sistematically performed before and after surgery, constituting as a matter of fact the decisive element indicating cerebral decompression.

Six patients (50 per cent) survived and 5 of them (41.6 per cent) had an excellent neurological and mental improvement. Considering these results, we think that a large bifrontal decompressive craniotomy is the best method of treatment in such cases, specially when performed precociously. These patients, however, need very special care after surgery, if possible in units of intensive therapy, owing to the large incidence of complications.

\section{REFERENCIAS}

1. AUSMAN, J. I.; ROGERS, C. \& SHARP, H. L. - Descompressive craniotomy for the encephalopathy of Reye's syndrome. Surg. Neurol. 6:97, 1976.

2. CLARK, K.; NASH, T. M. \& HUTCHISON, G. C. - The failure of circunferential craniotomy in acute traumatic cerebral swelling. J. Neurosurg. $29: 367,1968$.

3. CUSHING, H. - The establishment of cerebral hernia as a descompressive measure for inaccessible tumors, with the description of intermuscular methods of making the bone defect in temporal and occipital regions. Surg. Gynec. Obstet. 1:129, 1905.

4. GONÇALVES DA SILVA, J. A.; GONÇALVES DA SILVA, C. E. \& SOUSA, M. B. R. - Craniotomia descompressiva no edema cerebral grave: a propósito de 30 casos operados. Arq. Neuro-Psiquiat. (São Paulo) 34:232, 1976.

5. GURDJIAN, E. S. \& THOMAS, L. M. - Surgical management of the patient with head injury. Clin. Neurosurg. 12:56, 1964.

6. HORSLEY, V. - On the technique of operations on the central nervous system. Brit. med. J. $2: 411,1906$.

7. KJELLBERG, R. N. \& PRIETO, A. Jr. - Bifrontal decompressive craniotomy for massive cerebral edema. J. Neurosurg. $34: 488,1971$.

8. McKENSIE, K. G. - Glioblastoma: a point of view concerning treatment. Arch. Neurol. Psychiat. (Chicago) $36: 542,1936$.

9. MUNRO, D. \& SISON, W. R. - Hernia through the incisura of the tentorium cerebelli in connection with craniocerebral trauma. New Eng. J. Med. 247:699, 1952.

10. RANSOHOFF, J.; VALLO, B. M.; GAGE, E. L. Jr. \& EPSTEIN, F. - Hemicraniectomy in management of acute subdural hematoma. J. Neurosurg. 34:70, 1971.

11. SPILLER, W. G. \& FRAZIER, C. H. - Cerebral decompression: palliative operations in the treatment of tumors of the brain based on the observations of fourteen cases. J. Amer. med. Ass. 47:744, 1906.

Hospital da Beneficência Portuguesa - Rua Maestro Cardim 769, sala \&75 01323 São Paulo SP, Brasil 